\title{
Interpretative Vortex in Mansfield Park: A Check of "Figure-Ground" Theory from Deconstructive Perspective
}

\author{
Lu Jie $\mathrm{Ji}^{1,2}$ \\ ${ }^{1}$ Foreign Language College, Chengdu University of Information and Technology, China \\ ${ }^{2}$ College of Literature and Journalism, Sichuan University, China
}

Copyright $\bigcirc 2016$ by authors, all rights reserved. Authors agree that this article remains permanently open access under the terms of the Creative Commons Attribution License 4.0 International License

\begin{abstract}
Traditional "Figure-Ground" theory focuses on the mutual relationship between figures and grounds as well as reader's voluntary adjustment of their attention to change the stale orientation of the original figures and grounds. The essay checks the implement of "Figure-Ground" theory in Jane Austin's Mansfield Park from a deconstructive perspective and finds through the blending of figures and grounds, coexistence of primary and secondary figures as well as juxtaposition of grounds, many interpretative vortexes are created in the reader's interpretation of the text. These interpretative vortexes rejuvenate and modernize traditional classic literature by advocating freedom and vitality, opposing to order and rigidity, stressing pluralism and diversity, and objecting to unification as well as binary opposition.
\end{abstract}

Keywords Interpretative Vortex, Cognitive Poetics, Figure-Ground, Mansfield Park

\section{Introduction}

Jean Piaget pointed out that human's cognition on figures underwent three-stepped construction development which includes "in-figure", "inter-figure" and "out-figure". (Piaget 2005: 73 ).Piaget's theory on human's cognition on figures inspires the development of cognitive poetics' "figure-ground" theory. In China's cognitive poetics research field, "figure-ground" theory has drawn great academic attention because its employment in multidimensional textual analysis caters to the trend of "close reading" in the era of new criticism. This pair of relative concepts has made huge contribution for China's literature aestheticism after being sinicized. Inspired by Piaget's conclusion on human's three-stepped development in figure cognition, the author discovers that most Chinese researchers' employment of "figure-ground' theory still rests on "in-figure stage" and this traditional pattern is widely used to operate textual interpretation only. Few researchers try to explore the "inter-figure stage" that cares about the relations between figures or "out-figure stage" that cares about integral structure. The essay expands the traditional "figure-ground" theory to "inter-figure stage" and "out-figure stage" in analysis of Mansfield Park. The blending of figures and grounds, coexistence of primary and secondary figures as well as juxtaposition of grounds, corresponding to "in", "inter" and "out" stages are to be employed collectively to form a new "figure-ground" theory that allows various interpretations to coexist as paradoxes. Polysemy and ambiguity caused by this new "figure-ground" theory under deconstructive perspective bring about interpretative vortexes in literature aestheticism, which is literally in accordance with post-modern deconstructive kernel: encouraging freedom and vitality, fighting against authority and rigidity, stressing diversity and pluralism, opposing unification and binary opposition.

\section{Blending between figures and grounds in "In-Figure Stage"}

"Figure-ground relationship" is one of the most interesting issues in gestalt theory, both from the perceptual and the artistic point of view. In Cognitive Poetics(2002) Stockwell thought that "figure-ground" is the characteristic organization of perception into a figure that "stands out" against an undifferentiated ground (Stockwell 2002: 15) .In Texture: a Cognitive Aesthetic of Reading(2009) Stockwell insisted that figure and ground cognition is the key to attention, whether the object being attended to is a moving physical object or a virtual fictional one (Stockwell 2009: 9). In literature cognition, especially for novels, "characters" are often the focus of reader's attention in the textual world. Taking Mansfield Park as example, in the process of literature acceptance, traditional reader is liable to care more 
about the characterization, appearance and fate of protagonists or anti- protagonists, and regard settings as merely grounds for these characters' movement. Therefore, upright and wealthy Edmund, weak and virtuous Fannie, unrestrained Maria and Julia, frivolous and sophisticated Crawford, ignorant but self-sufficient Mrs Fannie, gentle but nervous Mrs. Bennet are all typical "figures" in Mansfield Park. When reader recognizes these characters as "figures" and the places as "grounds", he understands the diversity and complexity of human nature and the subtle and intricate interpersonal relationship. The theme "praising rationality and criticizing libido" can be drawn from the novel.

But the reader is endowed with the ability to adjust and control their attention autonomously, and they can make exchange between "figure" and "ground" by reducing their attention on characters and enhancing their attention on the environment description in the novel. For example, when the reader takes "characters" as "grounds" and "settings" as "figures", a brand-new perception comes into being. When the reader' attention focuses on "setting", some places in Mansfield Park obtain extraordinary meanings: Mansfield, magnificent and sumptuous, bright and spacious, noble and tidy, is the core of English spirit and the symbol of wisdom, reason, wealth and peace. Portsmouth, tumultuous and chaotic, impoverished and filthy, is the inhabitance of the vulgar and the ignorant and the symbol of deficiency of knowledge and poverty. London, prosperous but disordered, glitzy but corruptive is the representation of loss of faith and new belief in money instead of God. Antigua, full of darkness, riots and seductive treasure and fortune, is the island where Sir Thomas does colonial business and signifies the projection of English capitalists' desire for wealth and power.

When the reader abandons the convention of taking characters as figures and settings as grounds, and deliberately exchange their awareness degrees on them, Mansfield Park can be interpreted as a novel about the relationships of several settings in various spaces. While Mansfield park is just located in a place across two hemispheres, two oceans and four continents, so it is in a central point that is kept a watchful eye on (Said 2003: 84-109).John Wiltshire also noticed Jane Austin's excellent ability to "make the setting integral to her development of character" (John Wiltshire 2001:60). In this way, Mansfield Park is not only a geographical place providing a setting for the characters. It reflects a social and cultural belief, and symbolizes the essence of the England. It embodies the traditional English countryside value that is not contaminated by modern capitalism. It preserves the cozy and harmonious patriarchal ethic relation among different classes in the pre-industrial times. It implies the standard form of cultural hegemony that is carried out in the oversea colonies by British colonists. Willie van Peer and Eva Graf pointed out "Interest in the relationship of space and man can not only be traced back in time to the writings of Aristotle and other ancient thinkers, but it has also inspired people from widely different areas like the philosopher Kant or the physicist Newton - to name just a few-to reflect upon this subject..... The study of humans and space represents a vast and still growing area of research, an interdisciplinary meeting place for similar, but also opposing, ideas, methods and theoretical grounds" ( Semino \& Culpeper 2002:123-148 ) .Maybe it is because Jane Austin's clear awareness and deep insight on the relation between the characters and spaces that she entitled this common love story with the name of "Mansfield Park", a proper name for place.

However, if the reader just tries to get a new interpretation by the exchange of figures and grounds, they are woefully wrong. Actually, Stockwell developed his "Figure-ground" theory in an essay called Surreal figures. When he discussed figures in ground, he wrote: "Figures which fade into the ground by neglect can still be remembered, either unilaterally by the reader or with the active assistance of certain textual features. As described above, this can lead to some bizarre effects of 'felt absence', where an absence is tangible and paradoxically perceived as significantly present." (Gavins \& Steen 2003: 20). Inspired by surrealistic painting and sculpture, Stockwell's understandings about the relation between figures and grounds surpassed his predecessors' understanding about the relation between "foreground and ground" or "ground and figure". He admitted in this essay that he had been treating figure and ground fairly simply, as binary dimensions in a field, and he suggested that it might be fruitful to think in terms of a more graded texture of attention. In the light of this new instruction of cognition, firstly, the reader must think in terms of the continuity of the ground, which means that they should assume the continued existence of the ground behind the figure even when the figure obscures that part of the ground. Furthermore, when the reader thinks of a figure that is moving against the ground, they must keep track of the constantly changing patch of ground which is being occluded as the figure moves obstructively across it. Taking Mansfield Park as example, the textual worlds created by reader' cognition either by taking characters as figures and setting as ground, or setting as figures and characters as grounds are just like two parallel worlds in science fictions. But the two textual worlds are too independent from each other, which is obviously not in conformity with the complexity of real world. So to obtain new literature aestheticism through the exchange of figures and ground is just one-sided comprehension about Stockwell's theory. Under constructive perspective, figure and ground form a "binary opposition", in which the two opposite elements can never coexist and one is always in dominant position in terms of value, logic or significance. But from the second half of the $20^{\text {st }}$ century, the circle of literature and art trended to adopt a deconstructive perspective to create or analyze literature and art works. The new "figure-ground" theory under deconstructive perspective not only turns the hierarchical order upside down, but also tries to obscure the verge of figures and grounds. Stockwell said: "When a figure is perceived as being separate from the ground, it is interesting to consider what is 
happening at the edges and behind the figure" (Gavins \& Steen 2003: 20) .His interest in the verge of figures proves that the cognition under deconstructive perspective cares more about the knitting, entanglement and uncertainty of literature text. If the reader tries to explore Mansfield Park with this cognitive pattern, the original theme would be added to some ambiguous, hesitant and uncertain factors. In fact, most readers now still uses the "figure-ground" theory in "in-figure stage" under constructive perfective, and their interpretation about Mansfield Park is therefore relatively simple and shallow. Riffaterre encourages "retrospective reading" which means a reader can experience various cognitions towards one subject with the assistance of their previous reading experience (Riffaterre 1978:65). So with the first reading experience of taking characters or settings as "figures", reader has the potentials to blend "figures" and "grounds" together. In other words, in literature aestheticism and cognition, reader can dissect, destroy, overlay or reorganize figures and grounds to seek a richer and deeper connotation of the work in the "interpretative vortex". This would be a beneficial trial to construct a whole new textual world under deconstruct perspective.

\section{Coexistence of Primary and Secondary Figures in "Inter-Figure Stage"}

Piaget's research shows that the specific elements are lack of necessary relation in "in-figure" stage, or they only have limited relation, in which a certain status is regarded as the result of change of some elements partly. In "in-figure" stage, human's cognition about figures is restricted to shifting their attention from point $\mathrm{A}$ to point $\mathrm{B}$, and regarding the change of attention as the reason for the hermeneutic divergence. But in "inter-figure stage", humans begin to understand that the relation between different figures against the same ground, especial the relation between primary and secondary figures. Usually, if the ground doesn't change, the figures that are highlighted are not static or absolutely stabilized. Especially when figures with different quality or quantity coexist simultaneously in the same ground, primary and secondary figures are going to be differentiated due to the reader's concern extent. The shift between primary and secondary figures is to cause different interpretations about the same literature work. Taking Mansfield Park as example, traditional reader tends to take the description about the ethnics, conventions, morals, beliefs, society and culture in the $19^{\text {th }}$ century British countryside as background, take Fannie as primary figure since she is given much more detailed depiction by Jane Austin, and take other women around Fannie, such as Maria, Julia and Mary as secondary figures. Through this cognition pattern, the theme of Mansfield Park is often to be summarized as "happiness= wealth +rationality, unhappiness=selfishness +libido", because Fannie, a Cinderella with good temperament and rationality, finally gains Edmund's love and recognition of the whole family. While the other women all ends bad because of their unchecked passion. But Jane Austin wrote in 1813: "I have something in hand-which I hope on the credit of P.\&P. will sell well, tho' not half so entertaining." Her decision not repeat the "entertaining" formula of her most successful book suggests that, in Mansfield Park, she was aiming at something beyond easy approval(Janet Todd 2008:75). So this above over-simplified interpretation of the novel incurs some suspicions.

In the textual world formed by " $19^{\text {th }}$ century British countryside-Fannie-other women", the latter two's primary and secondary position is a pair of referential relation which means they are relative and changeable. Therefore, if the ground of " $19^{\text {th }}$ century British countryside" stays unchanged, reader's selection of different subjects as primary figures is to generate significant and even subversive influences on literature aestheticism and cognition. Reception aesthetics holds that for literature to happen, the reader is quite as vital as the author. Roman Ingarden calls the literary work itself merely as "schemata" or general direction which waits for reader to actualize. Shklovsky thinks "a work may be intended as prosaic and accepted as poetic, or intended as poetic and accepted as prosaic. This suggests that the artistry attributed to a given work results from the way we perceive it" (Shklovsky 1965:3-12). So literature aestheticism and cognition is not passive, on the contrary, it is an active process involved with reader's creation. When facing two or more aesthetic objects, reader's cognition obeys some basic laws: sharp contrast impresses. Scarry says "distraction and the recognition of attractors are dependent on various gestalt principles, plus various other determinants of prominence such as motion, animacy, functional intentionality, brightness, and size" (Scarry 2001). According to this cognitive mechanism, if compared with Maria, Julia and May, Fannie is weak, pale, silent and static, while the others are extroverted, talkative, energetic, and dynamic. Fannie is like a pencil sketch, while the others are like colorful oil paintings. Therefore reader's attention is very likely to be distracted from Fannie to the other women. If taking other women as primary figures and Fannie as secondary figure in the aestheticism and cognition of Mansfield Park, Fannie, Maria, Julia and Mary would be endowed brand-new meanings by the reader: Maria, Julia and Mary's chats, jokes, adventures, and disobedience show the reader the beauty of vitality after those women's breaking the joke of feudal moral and receiving capitalist humanistic thought; while Fannie's endurance, conservatism, caution and submission to patriarchy show the reader her lack of vitality and action, hence she would fall from the primary figure to secondary figure, or even be ignored as a "flat character". If a reader adopts this cognitive pattern to interpret Mansfield Park, a conclusion can be safely drawn: the much-touted Fannie is actually a moralist for old-fashioned feudalistic value, while the other much-clouted women are warriors for women equality and 
human purity. Although the other women stumble on their road to happiness, they still fight against their fates in the absurd world as Sisyphus did. So the theme of the novel can be regarded as "life meaning= freedom +fighting +libido". Zhu Hong, an expert in Jane Austin Study in China comments: "in manifesting modern spirit, Mansfield Park undoubtedly is very special and important" (Zhu Hong 1985:245). The "modern spirit" mention by Zhu Hong apparently refers to the modern feminist spirit embodied by "primary figures", such as Maria, Julia and Mary instead of the traditional male-dominant spirit conveyed by "secondary figure" like Fannie. When explaining reception aestheticism, Eagleton thinks as the reading proceeds, reader's expectations will themselves be modified by what they learn, and the hermeneutical circle will begin to revolve. "Striving to construct a coherent sense from the text, the reader will select and organize its elements into consistent wholes, excluding some and foregrounding others, concretizing certain items in certain ways; he or she will try to hold different perspectives within in the work, or shift from perspective in order to build up an integrated 'illusion"'(Eagleton 69). Eagleton's words exactly show us how reader selects figures from a ground, and how they rank these figures and how they filter some others. And through their creative understanding about these elements, an illusion of textual world comes into being in their minds.

However, if the reader just tries to get a new interpretation by the exchange of primary figure and secondary figures, it is far more enough. In post-modern era, criticism is placed under a "decentralized perspective". The orientation of primary and secondary figures is far more flexible and complicated than before. Except for the primary figure's falling down to the secondary and secondary figure's leaping up to the primary, sometimes all these figures can coexist in a ground without the evident distinction. Gestalt Psycology uses Necker cube to convince us that one cannot see the protruding and sunk squares simultaneously. That is to say, in cognition, if one adopts an interpretation way, in the meanwhile, he excludes the other possibility. But Ludwig Wittgenstein used Rabbit-duck illusion to prove its incorrectness. He held that it is impossible and unnecessary to adopt that kind of one-center and exclusive interpretation in aestheticism and cognition, actually duck and rabbit can coexist in human's mind (Wittgenstein 2001: 45). Under deconstructive perspective, in the aestheticism and cognition of Mansfield Park, the reader should not be confined by the traditional cognitive pattern of exchange between primary and secondary figure, because the dual interpretation brought by the entanglement and interknitting of them two can make reader linger in the interpretative vortex and gain great aesthetic satisfaction.

\section{Juxtaposition of Grounds in "Out-Figure Stage"}

Piaget thinks that in the "inter-figure" relation, separate figures are put in a space which includes them, while in "out-figure stage", some different systems are combined into the only entirety, and some reverent systems that are not combined initially are now combined into a simultaneous entirety (Piaget 2005: 84-85). The concepts of "entirety" in out-figure stage stressed by Piaget is just another expression for "ground" in "figure-ground" theory. When interpreting literature works, it's common to confine the concept of "ground" to some objects that are usually less obvious and conspicuous. For example, compared with characters, settings are often regarded as ground, just as being mentioned above. But this cognition convention limits the understanding about "ground" into the domain of "text", which is narrow and goes against the spirit of reception aestheticism that attaches great importance to the reader in literature aestheticism and cognition. In "out-figure stage", the reader should build up a microstructure by an extended meaning of "ground" which includes not only characters, settings, plots, but also themes, style, types of literature, etc. In Cognitive Stylistics, Willie van Peer and Eva Graf say "If cognitive linguistics is predicated on the idea that language use reflects cognitive mechanisms, then cognitive stylistics attempts to go one step further still, namely grounding stylistic variation in language use in cognitive processes too" (Semino \& Culpeper 2002:124). Taking Mansfield Park as example, if the reader takes the characters, settings and plots as "figures" in different grounds of themes, styles and types of literature, they would make a successful "defamiliarization". Zhao Yiheng wrote in his Semiotics: "recipients' minds are not just white papers waiting to be added signs; actually reading is not absolutely free. The recipients in the beginning recognize the types and styles of literature for the corresponding text, and then give some specific attention to them"(Zhao Yiheng 2012: 139). Vera Tobin regards reader's pre-understanding as "curse of knowledge" or "cognitive bias". He argued "the curse of knowledge is an artifact of a more general cognitive shortcut that is implicated in features of 'correct' sentence interpretation such as presupposition projection as well as in phenomena traditionally described as curse-of-knowledge errors" (Tobin 2). Their arguments add significance to the cognition of styles and themes in literature aestheticism. So if the reader take "love story" as ground for Mansfield Park, he cares more about the love affairs among the characters; if they take "bildungsroman" or "growth story" as ground, he cares more about the process of the protagonists' physical and psychological development; if he takes "post-colonial story" as its ground, he cares more about Sir Thomas' colonial business and some colonist deeds and words. For example, Fannie's words about her great interests in her uncle's colonial exploration would likely attract some criticism because some readers find them evidences to prove Fannie's loathsome colonial essence.

In "out-figure stage", the reader can get various understandings about author, work, world and himself by putting the text into various background of styles, themes and types of literature. This can be explained by Zhao 
Yiheng's words "the text is open to be interpreted, and it carries some 'self-contained metalanguage'......the conflicts between two different metalanguage collections lead to 'interpretative vortex"'(Zhao Yiheng 2012: 236-238). Because the complexity of a reader's personal experience and sociality itself determines his preunderstanding and expectation must be multiple and intricate, even one reader in his one-time effort of interpreting the novel, different metalanguages, such as "love story", "growth story" and "post-colonial story" can be juxtaposed and intermingled in reader's mind. The metalanguages in the same level work together, which leads different interpretations to coexist in paradoxes. This open and deconstructive interpretation brings charm for traditional literature in modern criticism. Merely through the juxtaposition of different grounds (in broad sense), interpretative vortexes are to be created and bring about vitality to traditional literature.

\section{Conclusions}

"Mansfield Park is in many ways the most interesting and the most complex of all Jane Aistin's novels"(Helen Lefroy 1997: 126) said by Helen Lefroy, a biographer for Jane Austin. So the novel attracts researchers and readers' unabated passion and interpretation. But their previous conclusions on this classic work leave "anxiety of influence" to the subsequent researchers and readers. Shklovsky believes "if we start to examine the general laws of perception, we see that as perception becomes habitual, it becomes automatic" (Shklovsky 1965:3-12), that is to say, a reader's interpretive habit would also hinder him from getting new aestheticism. Therefore, in literature aestheticism and cognition, one must cast off some habitual pattern both imposed by his predecessors and himself. Inspired by Piaget's three stages of human's cognition on figures, the essay explores a new pattern of employing "figure-ground" theory, which includes the blending of figures and grounds, coexistence of primary and secondary figures as well as juxtaposition of grounds. "A literary text is the integration of form, meaning and aesthetic value"(Xiong Muqing: 448), Figure-ground theory under deconstructive perspective is a new analytical paradigm and acquisition of meaning, which make it possible for the reader to interpret the literature work from different dimensions and approach new aestheticism in amazing interpretative vortexes.

\section{Acknowledgments and Legal Responsibility}

This essay is an achievement of the project "the Research on the Prospect of Poetry in Network Era" (WLWH15-17) supported by chief research base of Sichuan Provincial Department of Education: network culture research center. I am grateful to the fund to enable me to make research for this project.

\section{REFERENCES}

[1] Copeland, Edwaed \& Juliet Mcmaster (eds.).(2008).Mansfield Park, Emma, Persuasion[A]. The Cambridge Companion to Jane Austin [A]. Shanghai: Shanghai Foreign Language Education Press.

[2] Eagleton, Terry. (2004).Literary Theory: An Introduction,[M]. Beijing: Foreign Language Teaching and Research Press.

[3] Gavins, Joanna \& Gerard Steen (eds.). (2003). Surreal figures [A]. Cognitive Poetics in Practice [C]. London: Routledge press.

[4] Lefroy, Helen. (2002). Jane Austin [M].Beijing: Foreign Language Teaching and Research Press.

[5] Riffaterre, Michael.(1978).Semiotics of Poetry[M]. Bloomington \& London: Indiana University Press.

[6] Scarry, E. (2001).Dreaming by the Book [M].Princeton, NJ: Princeton University Press.

[7] Semino, Elena\& Jonathan Culpeper (eds.). (2002).Between the lines: Spatial language and its developmental representation in Stephen King's IT [A]. Cognitive Stylistics: Language and Cognition in Text Analysis[C].Amserdam: John Benjamins Publishing Company.

[8] Shklovsky, V. (1965). Art as Technique [A]. InL.Lemon \& M.Reis(eds. ). Russian Formalist Criticism [C]. Lincoln: Nebraska University Press.

[9] Stockwell, Peter. (2002). Cognitive Poetics: An Introduction [M]. London \&New York: Routledge press.

[10] Stockwell, Peter. (2009). Texture a Cognitive Aesthetic of Reading [M]. Edinburgh University Press Ltd..

[11] Tobin, Vera. (2009).Cognitive bias and the poetics of surprise [A]. Language and Literature [C]. Sage publication.

[12] Todd, Janet. (2008). The Cambridge Introduction to Jane Austin $[\mathrm{M}]$. Shanghai: Shanghai Foreign Language Education Press.

[13] Wittgenstein, Ludwig. (2001). Philosophical Investigation[M]. London: Blackwell Publisher.

[14] Edward Wadie Said. (2003). Culture and Imperialism[M].Trans.Li Kun. Beijing: The Joint Publishing Company Ltd.,

[15] Jean Piaget (2005).Psychology and the history of science[M] Trans. Jiang Zhihui. Shanghai: East China Normal University Press.

[16] Xiong Muqing. (2012).A cognitive analytic method "from interpretation to discovery" -an example of "The Eagle" [J]. Foreign Language and Research.

[17] Zhu Hong. (1985).Jane Austin Study [M]. Beijing: China Federation of Literary and Art Circles Publishing Corporation.

[18] Zhao Yiheng. (2012). Semiotics[M]. Nanjing: Nanjing University Press. 